\title{
Prediction of Earthquakes; Considering the Ratio of $P$-to-S Wave Velocities
}

\author{
Huseyin Murat Cekirge ${ }^{1,2}$ \\ ${ }^{1}$ Mechanical Engineering, New York University, Brooklyn, USA \\ ${ }^{2}$ Mechanical Engineering, City College of New York, City University of New York, New York, USA
}

\section{Email address:}

hmcekirge@nyu.edu

\section{To cite this article:}

Huseyin Murat Cekirge. Prediction of Earthquakes; Considering the Ratio of P-to-S Wave Velocities. Earth Sciences. Vol. 9, No. 6, 2020, pp. 227-231. doi: 10.11648/j.earth.20200906.11

Received: November 27, 2020; Accepted: December 9, 2020; Published: December 16, 2020

\begin{abstract}
The ratio of P-to-S-wave velocities $(V p / V s)$ is considered as one of the important measures of stressed natural rocks. The changes of this ratio were observed in various earthquakes, however the time of occurrence of the earthquakes were not determined, since the predictions were not combined with other prediction methods. This discriminant provides information about formation and evolution of composition for the earth's crust. In addition, the changes in $V p / V s$ before and after earthquakes are the possibly reliable direction to realizing the mechanics and probably predicting earthquakes. However, due to lattice orientations of anisotropic minerals, most of earth's rocks are anisotropic and there exist cracks and thin layerings. The changing patterns in $V p / V s$ acquired from seismic propagations can be readily analyzed according to the ray path and the polarization of the (P) pressure and (S) shear waves. The variations in their ratios carry information about stress variations of THE crust of the earth. The arising stresses in rocks are the messengers of possible earthquakes. The stations with monitoring devices and Geographical Positioning System (GPS) upgraded WI-FI remote data acquisition system can serve monitoring stress and movements in the earth's crust. In view present technological developments, the system is reasonable cost effective and prediction of earthquakes can be possible in narrowed time interval. The laboratory tests will be also part of the prediction process.
\end{abstract}

Keywords: P Waves, S Waves, Earthquake Predictions, Rayleigh Waves, Love Waves, Material Constants

\section{Introduction}

Earthquakes are causing many devastations and deaths every year. Unfortunately, there is no scientific prediction methods does exist so far, Lomnitz [1], Hough [2], Gullu [3], Aggarwal et al. [4], Verdugo [5], Liu et al. [6], Sara [7] and Crampin et al. [8]. Earthquakes are sudden and unexpected events and predictions are far away from reality. Prediction of earthquakes and their determination of the epicenter are important to minimize their damage to dwellings on the earth. Few methods can be mentioned, such as watching historical earthquake data, microtremor data, emission of radon gas in the area, observing movement of animals, etc. In this paper, the change of ratio $V_{p} / V_{s}$, Cekirge [9], that is velocities of pressure and shear waves is explained while they are traveling through the earth's crust. These waves are carrying information from the earth's crust. These velocities are function of material constants of the medium in that the waves are travelling. If the stress arises and accumulates in the medium where these waves propagate, the material constants are being exposed to change. The detection of stress field, that causes the earthquake, brings very important information about occurrence of earthquakes, Passelègue et al. [10], Ohnaka [11] and Vassiliou and Kanamori [12]. As stated in Wang et al. [13]; the conventional criteria for $V_{p} / V_{s}$ ratio are $V_{\mathrm{p}} / V_{\mathrm{s}} \leq 1.756$ for felsic rocks, $1.756<V_{p} / V_{s} \leq 1.809$ for intermediate rocks, $1.809<V_{p} / V_{s} \leq 1.944$ for mafic rocks, and $V_{\mathrm{p}} / V_{\mathrm{s}}>1.944$ fluidfilled porous/fractured or partially molten rocks. Seismic waves and their dynamic were studied in depth and the arising stress is the feature of these activities, Aki and Richards [14] and Lowrie [15]. There are abundant studies between seismic waves and earthquakes, Okamoto et al. [16] and Takemura et al.[17]. The seismic waves propagate in nonhomogeneous and anisotropic media; it is response of the stressed of the medium. Propagation patterns between $\mathrm{P}$ and $\mathrm{S}$ waves are the diagnostics of the medium where these waves propagate. These patterns are distorted with the rising stress field in the medium. The observation of these could be used as a 
stethoscope for the earth's crust.

The governing equations for the media where $\mathrm{P}$ and $\mathrm{S}$ waves propagate are presented Koh and Eringen [18], Green and Zerna [19] and Eringen [20]. The P and S waves are small amplitude waves propagating initially stressed media, the propagation of these small amplitude harmonic waves in an initially stressed media were developed by Hayes and Rivlin [21] for elastic; Flavin and Green [22] for viscoelastic; and Hayes and Rivlin [23], Cekirge and Suhubi [24], Suhubi [25] and Chadwick [26] for thermoelastic materials. The waves are propagating in a medium that is subjected to respectively large static deformations, the State D, Figure 1; with the seismic disturbances, the State $\mathrm{S}$. These stresses are the cause of the changing material constants of the medium. It is assumed that the time dependent harmonic deformations superposed on the deformed state D. The disturbances are sufficiently small and second order terms are neglected while the governing equations are being developed. The propagation of harmonic plane waves is considered in this initially stressed compressible medium. Through perturbation techniques, the governing equations are being solved up to second order that is providing sufficient accuracy for the these seismic waves. The detailed analyses of the governing equations are given in these references.

\section{Analysis}

\subsection{Wave Propagation in Deformed State}

In State $\mathrm{D}$, the body in static equilibrium,

$$
\mathrm{T}_{\mathrm{ij}, \mathrm{k}}=0 \text {, }
$$

where,

$\mathrm{T}_{\mathrm{ij}}=$ stress components in State $\mathrm{D}$, and

$\mathrm{i}, \mathrm{j}$ and $\mathrm{k}=$ indices.

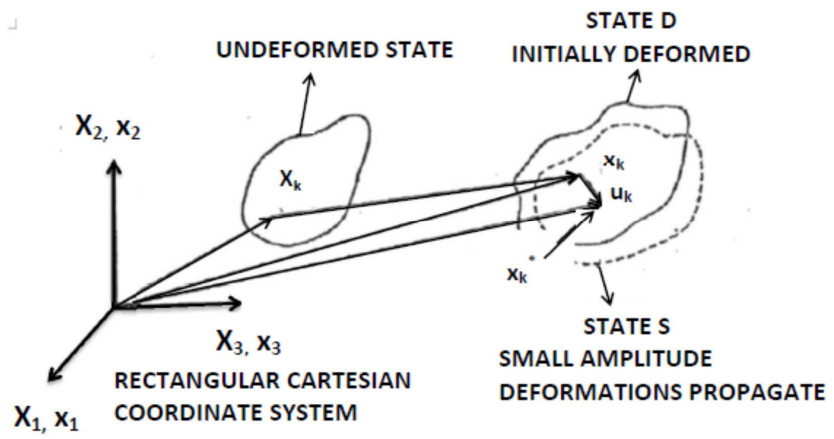

Figure 1. Various deformation states of the medium.

A further time dependent deformation is considered and the particle $\mathrm{x}_{\mathrm{k}}$ moves to $\mathrm{x}_{\mathrm{k}}{ }^{*}$ as,

$$
\mathrm{x}_{\mathrm{k}}^{*}=\mathrm{x}_{\mathrm{k}}+\varepsilon \mathrm{u}\left(\mathrm{x}_{\mathrm{i}}, \mathrm{t}\right),
$$

where,

$\varepsilon=$ perturbation variable, and

$\mathrm{t}=$ time.

The resulting state is State $\mathrm{S}$, where stress field becomes

$\mathrm{T}+\varepsilon \mathrm{t}^{*}, \mathrm{t}^{*}$ is the superposed stress field due small amplitude disturbances in State D, Green and Zerna [12] and
Suhubi [8]. If we consider earth's crust isotropic and homogenous medium, the Hook's law can be written as,

$$
\mathrm{t}_{\mathrm{ij}}^{*}=\eta \mathrm{e}_{\mathrm{kk}} \delta_{\mathrm{ij}}+2 \mu \mathrm{e}_{\mathrm{ij}}
$$

where,

$$
\begin{aligned}
& \mathrm{t}_{\mathrm{ij}}{ }^{*}=\text { stress components in State } \mathrm{S}, \\
& \mathrm{i}, \mathrm{j} \text { and } \mathrm{k}=\text { indices, } \\
& \mathrm{e}_{\mathrm{ij}}=\text { deformation components, } \\
& \delta_{\mathrm{ij}}=\text { Kronecker delta, }\left(\delta_{\mathrm{ij}}=1,\right. \\
& \text { if } \left.\mathrm{i}=\mathrm{j} \text {, and } \delta_{\mathrm{ij}}=0 \text { if } \mathrm{i} \neq \mathrm{j}\right), \\
& \eta \text { and } \mu=\text { material constants, and } \\
& \mathrm{u}_{\mathrm{i}}=\text { the displacements in State } \mathrm{S} \text { along } \mathrm{x}_{\mathrm{i}} \text { directions, } \mathrm{i}=1 \text {, }
\end{aligned}
$$
2 and 3.

It should be mentioned that the material constants are being changed due stress filed T. The deformations in term of displacements $\mathrm{u}_{\mathrm{i}}$ 's, which are particle movements in State $\mathrm{S}$,

$$
\mathrm{e}_{\mathrm{ij}}=(1 / 2)\left(\partial \mathrm{u}_{\mathrm{i}} / \partial \mathrm{x}_{\mathrm{j}}+\partial \mathrm{u}_{\mathrm{j}} / \partial \mathrm{x}_{\mathrm{i}}\right)
$$

where,

$\mathrm{e}_{\mathrm{ij}}=$ strain components.

With initial strains, Equation (1) is written as,

$$
\rho\left(\partial^{2} u_{i} / \partial t^{2}\right)=\partial t_{i j}{ }^{*} / \partial x_{i}+u_{i, j k} T_{j k}+u_{j, j k} T_{i k}
$$

where,

$\mathrm{u}_{\mathrm{i}}=$ displacements from undeformed state to State $\mathrm{S}$,

$\rho=$ material density in State $D$, and

$\mathrm{t}=$ time.

Equations (2) and (5) can result as

$$
\mu u_{i, j j}+(\mu+v) u_{j, j i}=\rho\left(\partial^{2} u_{i} / \partial t^{2}\right),
$$

If the displacements $\mathrm{u}_{1}, \mathrm{u}_{2}$ and $\mathrm{u}_{3}$ are in the directions of $x_{1}, x_{2}$, and $x_{3}$, Equation (6) has the solution in the following:

a) Longitudal waves, $P$ waves;

$$
\begin{gathered}
\mathrm{u}_{1}=\mathrm{a} \sin \left[(2 \pi / \mathrm{l})\left(\mathrm{x}_{1} \pm \mathrm{v}_{\mathrm{p}} \mathrm{t}\right)\right], \\
\mathrm{u}_{2}=0 \\
\mathrm{u}_{3}=0 .
\end{gathered}
$$

where,

$\mathrm{a}=$ amplitude of the wave,

$\pi=3.141 \ldots$

$1=$ wave length,

$\mathrm{v}=$ wave velocity of longitudal waves, and

$$
\left.\mathrm{v}_{\mathrm{p}}=\mathrm{a}[(\eta+2 \mu) / \rho)\right]^{1 / 2}
$$

b) Transversal waves, $\mathrm{S}$ waves;

$$
\begin{gathered}
\mathrm{u}_{1}=0, \\
\mathrm{u}_{2}=\mathrm{a} \sin \left[(2 \pi / \mathrm{l})\left(\mathrm{x}_{1} \pm \mathrm{v}_{\mathrm{s}} \mathrm{t}\right)\right], \\
\mathrm{u}_{3}=0,
\end{gathered}
$$

and

$$
\mathrm{v}_{\mathrm{s}}=(\mu / \rho)^{1 / 2}
$$


where,

c) Surface waves;

$$
\begin{gathered}
\mathrm{u}_{1}=0, \\
\mathrm{u}_{2}=0, \\
\mathrm{u}_{3}=\mathrm{a} \sin \left[(2 \pi / \mathrm{l})\left(\mathrm{x}_{1} \pm \mathrm{v}_{\text {sur }} \mathrm{t}\right)\right],
\end{gathered}
$$

where,

$\mathrm{v}_{\text {sur }}=$ wave velocity,

which is a plane wave propagating with the speed of $v_{\text {sur }}$ in $x_{3}$ direction.
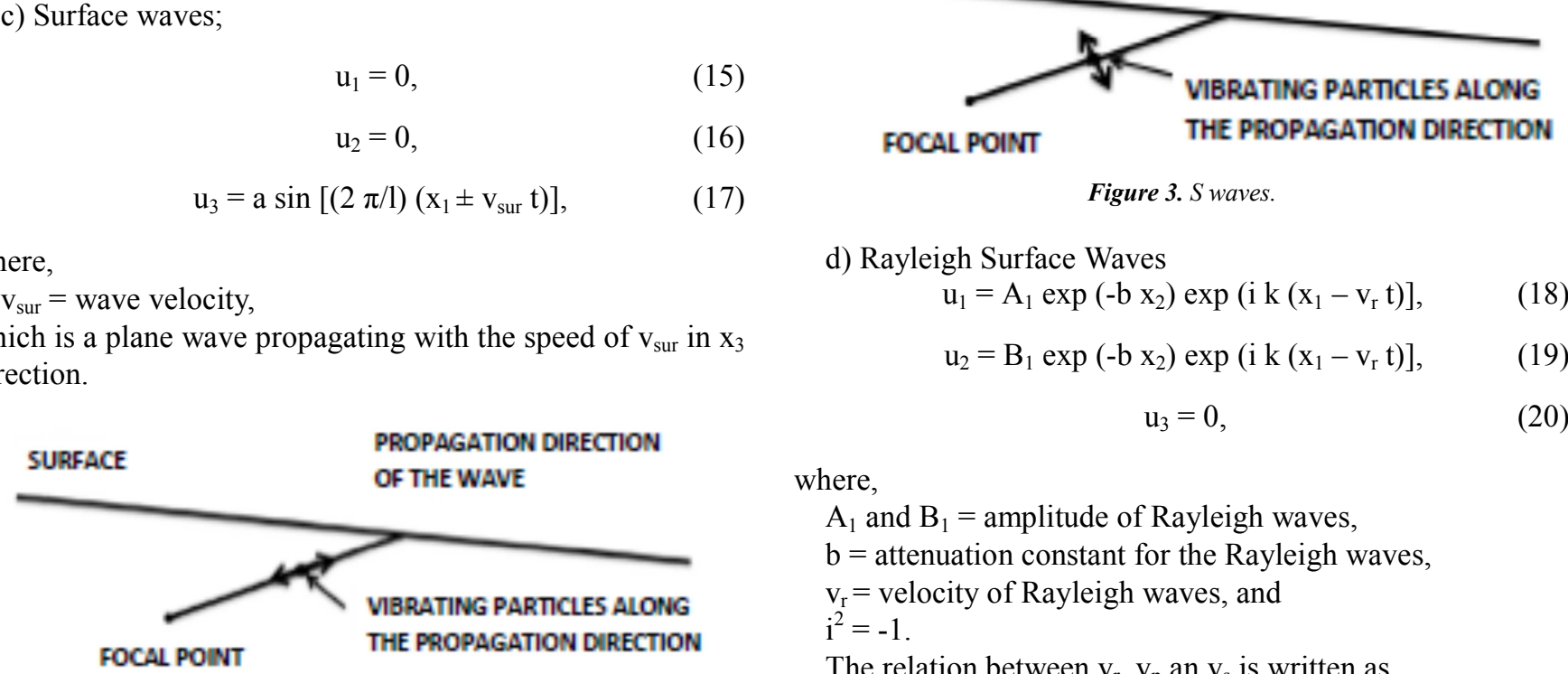

Figure 3. $S$ waves.

d) Rayleigh Surface Waves

$$
\begin{gathered}
\mathrm{u}_{1}=\mathrm{A}_{1} \exp \left(-\mathrm{b} \mathrm{x}_{2}\right) \exp \left(\mathrm{ik}\left(\mathrm{x}_{1}-\mathrm{v}_{\mathrm{r}} \mathrm{t}\right)\right] \\
\mathrm{u}_{2}=\mathrm{B}_{1} \exp \left(-\mathrm{b} \mathrm{x}_{2}\right) \exp \left(\mathrm{ik}\left(\mathrm{x}_{1}-\mathrm{v}_{\mathrm{r}} \mathrm{t}\right)\right] \\
\mathrm{u}_{3}=0,
\end{gathered}
$$

where,

$\mathrm{A}_{1}$ and $\mathrm{B}_{1}=$ amplitude of Rayleigh waves,

$\mathrm{b}=$ attenuation constant for the Rayleigh waves,

$\mathrm{V}_{\mathrm{r}}=$ velocity of Rayleigh waves, and

$i^{2}=-1$.

The relation between $\mathrm{v}_{\mathrm{r}}, \mathrm{v}_{\mathrm{p}}$ an $\mathrm{v}_{\mathrm{s}}$ is written as,

Figure 2. $P$ waves.

$$
\left.\left(\mathrm{v}_{\mathrm{r}}^{6} / \mathrm{v}_{\mathrm{s}}{ }^{6}\right)-8\left(\mathrm{v}_{\mathrm{r}}^{4} / \mathrm{v}_{\mathrm{s}}^{4}\right)+\mathrm{v}_{\mathrm{r}}{ }^{2}\left[\left(24 / \mathrm{v}_{\mathrm{s}}{ }^{4}\right)-16 / \mathrm{v}_{\mathrm{p}}{ }^{2}\right)\right]-16\left[1-\left(\mathrm{v}_{\mathrm{s}}^{2} / \mathrm{v}_{\mathrm{p}}{ }^{2}\right)\right]=0,
$$

and the relation between the ratios of $v_{r} / v_{p}, v_{s} / v_{p}$ and $\mathrm{v}_{\mathrm{r}} / \mathrm{v}_{\mathrm{S}}$ to Poisson ratio, which is material constant, is presented by Figure 4.

e) Love Surface waves

$$
\begin{gathered}
\mathrm{u}_{1}=0, \\
\mathrm{u}_{2}=0, \\
\mathrm{u}_{3}=\mathrm{A}_{3} \exp \left(-\mathrm{b} \mathrm{x}_{2}\right) \exp \left(\mathrm{i} \mathrm{k}\left(\mathrm{x}_{1}-\mathrm{v}_{\mathrm{L}} \mathrm{t}\right)\right],
\end{gathered}
$$

where,

$\mathrm{A}_{3}=$ Amplitude of Love waves,

$\mathrm{b}=$ Attenuation constant for the Love waves, and $\mathrm{v}_{\mathrm{L}}=$ velocity of Love waves.

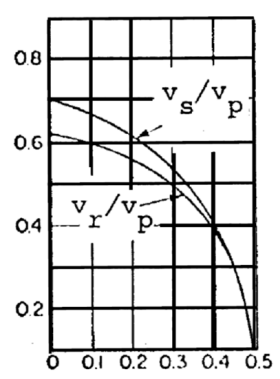

$v$ ratio

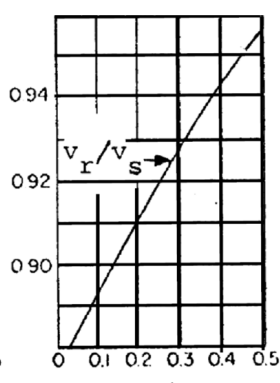

$v$ ratio
Figure 4. The relation between $v$, Poisson ratio, between $v_{s}, / v_{p}, v_{r}, v_{p}$ and $v_{r}, v_{s}$.

$v_{r} / v_{p}$ and $v_{r} / v_{s}$

The relation defines $v_{\mathrm{L}}$ is,

$$
\mu\left[1-\left(\mathrm{v}_{\mathrm{L}} / \mathrm{v}_{\mathrm{s}}\right)^{2}\right]^{1 / 2}-\mu_{1}\left[\left(\mathrm{v}_{\mathrm{L}} / \mathrm{v}_{\mathrm{s}}\right)^{2}-1\right]^{1 / 2} \tan \left\{\mathrm{kH}_{1}\left[\left(\mathrm{v}_{\mathrm{L}} / \mathrm{v}_{\mathrm{s}}\right)^{1}-1\right]^{1 / 2}\right\}=0
$$

where,

$\mu=$ material constants in semi-infinite medium,

$$
\mathrm{u}=\nabla \varphi+\nabla \mathrm{x} \psi
$$

$\mu 1=$ material constant in the layer,

vs $=$ velocity of s wave in semi-infinite medium,

$\mathrm{vs}^{1}=$ velocity $\mathrm{s}$ waves in the layer, and

$\mathrm{H}_{1}=$ thickness of the layer.

\subsection{Wave Propagation with Displacement Potentials}

Based on the Helmholtz theorem Malvern [27], the vectorial field $\mathrm{u}_{\mathrm{i}}$ can be expressed as

$$
\mathrm{u}_{\mathrm{i}}=\varphi, \mathrm{i}+\mathrm{e}_{\mathrm{ijk}} \psi_{\mathrm{k}, \mathrm{j}}
$$

where,

$\Phi=$ scalar potential,

$\psi=$ vector potential,

$\varepsilon_{\mathrm{ijk}}=$ permutation symbol,

$\nabla=$ gradient operator, and

$\nabla \mathrm{x}=$ rotation operator, and

The permutation symbol is

$$
\varepsilon_{123}=\varepsilon_{231}=\varepsilon_{312}=1, \varepsilon_{132}=\varepsilon_{213}=\varepsilon_{321}=-1
$$

and others $\varepsilon_{\mathrm{ijk}}=0$.

or

$$
\rho \partial\left(\partial^{2} \varphi / \partial \mathrm{t}^{2}\right) / \partial \mathrm{x}_{\mathrm{i}}+\rho \varepsilon_{\mathrm{ijk}} \partial\left(\partial^{2} \psi_{\mathrm{k}} / \partial \mathrm{t}^{2}\right) / \partial \mathrm{x}_{\mathrm{j}}=(\eta+2 \mu) \partial\left(\nabla^{2} \varphi\right) / \partial \mathrm{x}_{\mathrm{i}}+\mu \varepsilon_{\mathrm{ijk}} \partial\left(\nabla^{2} \psi_{\mathrm{k}}\right) / \partial \mathrm{x}_{\mathrm{j}},
$$


where,

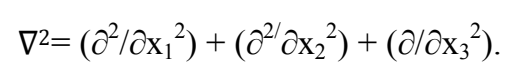

$\nabla^{2}$ is the Laplacian operator, and

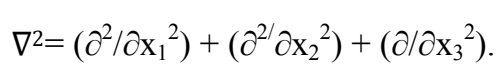

Since displacements are too small, and as a result, the material density is considered as constant. Then, equation (2.20) is separated for presenting the following waves,

$$
\nabla^{2} \varphi=\left(1 / \mathrm{v}_{\mathrm{p}}{ }^{2}\right)\left(\partial^{2} \varphi / \partial \mathrm{t}^{2}\right),
$$

and

$$
\nabla^{2} \psi_{\mathrm{k}}=\left(1 / \mathrm{v}_{\mathrm{s}}^{2}\right) \partial^{2} \psi_{\mathrm{k}} / \partial \mathrm{t}^{2}
$$

In these equations,

$$
\mathrm{v}_{\mathrm{p}}=[(\eta+2 \mu) / \rho]^{1 / 2},
$$

and

$$
\mathrm{v}_{\mathrm{s}}=(\mu / \rho)^{1 / 2} .
$$

These wave velocities are function of material constant in State D, where the material constants are differing respect to material constants in undeformed state. The comparative studies can generate information for arising stress field and ultimately, possible earthquakes. Of course, the predictions require comparative studies for arising stress field.

\section{Rate of Changing Stress Field}

The idea is the not only for determining the arising stress field, also evolution of the rate of arising field since the stress field is being monitored and recorded in the field as time series. The failure criteria can determine the breaking point of the material. Since the rate of stress field is monitored, the time of the failure or the earthquake could be predicted or determined at time within an interval of tolerance.

Since time dependent behavior for stress field is monitored, it is possible determining the time of breaking or failure time of the formation. The material may reach the failure point at predicted or determined time; that is the earthquake. The material failure theories for ductile and brittle materials such as maximum shearing stress, (Tresca), maximum distortion energy (Von Mises), maximum normal stress (Coulomb) and maximum normal strain (Saint-Venant) theories or combination of these could be used, Beer et al. [28], Christensen [29], Timoshenko [30], Hearn [31], Makhlouf and AliofKhazraei [32] and Buehler [33]. The combination of these theories could be used to determine failure time by considering material structure of the area under consideration. The randomness of material constants in the geological structures will also be accounted for determining expected time of earthquake with its variance. This consideration will result a time interval of occurrence of the earthquake with a confidence. The key factor is determining arising stress field

and its growing rate. These criteria, of course, should be supported by field observations, material samplings and laboratory studies. These methodologies are aiming at the predicting time and shortening time interval of occurrences of earthquakes. It should be noted that there is a tolerance cushion of time in these predictions.

\section{Conclusions}

Seismic disturbances are being observed by the stations that can estimate velocities of $\mathrm{P}$ and $\mathrm{S}$ waves. These values and their ratios are containing in information from depths of the earth's crust. Changes in these values are the messengers of the seismic activities in the earth's crust. These values can be compared with sample values taken from the earth's crust, the compared values are material constants and wave velocities. It is necessary to establish a network to observe these waves, the movements earth's can be measured in these stations as well. Of course, several methods should be used for the prediction of earthquakes accompanied with geology of the area. The heterogeneity, anisotropy and layered structure exist in the medium, and these factors less effective than information of the stress that is carried by the infinite small amplitude waves.

The information about structure of the area is respectively unchanging situation in the medium. Essentially, these waves carry information about the changing and arising stress field in the medium. A network of stress monitoring with Geographical Positioning System (GPS) stations around earthquakes zones could be cost effective since this system can utilize a remote WI-FI data acquisition system. In these stations, the stress field and earth movements can be monitored around the clock for predicting earthquakes.

\section{References}

[1] Cinna Lomnitz, Fundamentals of earthquake prediction, John Wiley, New York, 1994.

[2] Susan E. Hough, Predicting the Unpredictable: The Tumultuous Science of Earthquake Prediction, Princeton University Press, ISBN 9780691173306, 2016.

[3] H. Güllü, "On the prediction of shear wave velocity at local site of strong ground motion stations: an application using artificial intelligence", Bulletin of Earthquake Engineering, 11: 969-997, doi: 10.1007/s10518-013-9425-8, 2013.

[4] Yash P. Aggarwal, Sykes, Lynn R., Simpson, "David W., Richards, Paul G., "Spatial and temporal variations in $\mathrm{t} \mathrm{s} / \mathrm{t} \mathrm{p}$ and in P wave residuals at Blue Mountain Lake, New York: Application to earthquake prediction", Journal of Geophysical Research, Vol. 80, No. 5, doi: 10.1029/jb080i005p00718, 1975.

[5] Ramón Verdugo, "Experimental and conceptual evidence about the limitations of shear wave velocity to predict liquefaction", Soil Dynamics and Earthquake Engineering, doi: 10.1016/j.soildyn.2016.09.046, 2016. 
[6] Hong-gui Liu, Wang, Pei-ling, Yang, Cai-xia, Xu Ge, Sun Ye-jun, Chen, Zhang-li, Zheng, Si-hua. "Application of apparent stress in earthquake prediction", Acta Seismologica Sinica Vol. 20 No. 4 (467 476), doi: 10.1007/s11589-0070467-3, 2007.

[7] Amoroso Sara. "Prediction of the shear wave velocity VS from CPT and DMT at research sites", Frontiers of Structural and Civil Engineering, 8, doi: 10.1007/s11709-013-0234-6, 2014.

[8] Stuart Crampin, Booth, David C., Evans, Russ, Peacock, Sheila, Fletcher, Jon B., Comment on "Quantitative measurements of shear wave polarizations at the Anza Seismic Network, southern California: Implications for shear wave splitting and earthquake prediction" by Richard C. Aster, Peter M. Shearer, and Jon Berger, Journal of Geophysical Research, Vol. 96, No. B4, pp 6403-6414, doi: 10.1029/90jb02453, 1991.

[9] H. M. Cekirge, Prediction of Earthquakes by Observing Changes in Seismic Wave Velocities (Turkish), Thesis for Dozentship, Bogazici University, Istanbul, 1979.

[10] François X. Passelègue, Michelle, A., Pierre D., Fabian B., Jérôme F. and Marie V.," Initial Effective Stress Controls the Nature of Earthquakes", Nature Communications, 11: 5132, 2020, https://doi.org/10.1038/s41467-020-18937-0

[11] M. Ohnaka. The Physics of Rock Failure and Earthquakes. Cambridge University Press. p. 148. ISBN 978-1-107-355330,2013

[12] Marius Vassiliou and Kanamori, H., "The Energy Release in Earthquakes”, Bull. Seismol. Soc. Am. 72: 371-387, 1982.

[13] Qian Wang, Zhiqin, X. U. and Shaocheng, J. I., "Vp/Vs Anisotropy and Implications for Crustal Composition Identification and Earthquake Prediction", Acta Geologica Sinica - English Edition. Volume 83, Issue 4, 2009.

[14] Keiiti Aki and Richards, P. G., Quantitative seismology, 2nd edn. University Science Books, Freeman, San Francisco, 2002.

[15] William Lowrie, "The Fundamentals of Geophysics", Cambridge University Press, 1997.

[16] Kyosuke Okamoto, Yi, L., Asanuma, H., Okabe, T., Abe, Y. and Tsuzuki, M., "Triggering processes of Microseismic Events Associated with Water Injection in Okuaizu Geothermal Field, Japan, Earth, Planets and Space”, volume 70, Article number: 15, 2018.

[17] Shunsuke Takemura, Kobayashi, M. and Yoshimoto, K., "Prediction of Maximum P- and S-Wave Amplitude Distributions Incorporating Frequency- and DistanceDependent Characteristics of the Observed Apparent Radiation Patterns", Earth, Planets and Space volume 68, Article number: 166. 2016.
[18] S. L. Koh and Eringen, A. C., On the Foundation of Nonlinear Thermo-Viscoelasticity, Int. J. Engr. Sci., 1, 199-229, 1963.

[19] A. E. Green and Zerna, W., Theoretical Elasticity, Oxford University Press, 1954.

[20] A. C. Eringen, Mechanics of Continua, John Wiley and Sons, Inc., New York, 1967.

[21] M. Hayes and Rivlin, R. S., "Propagation of a Plane Wave in an Isotropic Elastic Material Subjected to Pure Homogeneous Deformation”, Arch. Rat. Mech. Analysis, 8, 15-22, 1961.

[22] J. N. Flavin and Green, A. E.; "Plane Thermo-elastic Waves in an Initially Stresses Medium", J. Mech. Phys. Solids, 179 190, 1961.

[23] M. A. Hayes and Rivlin, R. S., "Propagation of Sinusoidal Small-Amplitude Waves in a Deformed Viscoeleastic Solid I", J. Acoust. Soc. Amer., 46, 610-616, 1969.

[24] H. M. Cekirge and Suhubi, E. S., "Propagation of a Plane Wave in an Initially Stressed Thermoelastic Medium", Bulletin of the Technical University of Istanbul, Vol. 27, 1, 1974.

[25] E. S. Suhubi, Thermoelastic Solids, Continuum Physics, Vol. II, Ch. 2, edit. by A. C. Eringen. Academic Press, 1976.

[26] P. Chadwick, Thermoelasticity, Dynamical Theory, Ch. VI in Progress in Solid Mechanics, Vol. I, edit. I. N. Sneddon and R. Hill, North-Holland Publishing Co., Amsterdam, 1960.

[27] L. E. Malvern, Introduction to the Mechanics of a Continuous Medium, Englewood Cliffs, N. J., Prentice Hall, Inc., 1969.

[28] Ferdinand P. Beer, Johnston Jr. E. R, Jr., DeWolf J. T. and Mazurek D. F., Mechanics of Materials, Eighth Ed., McGrawHill, 2020.

[29] R. M. Christensen, The Theory of Materials Failure, Oxford University Press, 2013.

[30] S. P. Timoshenko, Strength of Materials. Advanced Theory and Problems, D. Van Nostrand Company, Inc., New York, 1948.

[31] E. J. Hearn, Mechanics of materials: an introduction to the mechanics of elastic and plastic deformation of solids and structural materials, Vol.1-2, Third ed. ButterworthHeinemann, Oxford, 1997.

[32] Abdel Salam Hamdy Makhlouf and Aliof Khazraei, M.., edit. Handbook of materials failure analysis: with case studies from the oil and gas industry, Butterworth-Heinemann is an imprint of Elsevier, Amsterdam, 2016.

[33] Markus J. Buehler (ed.), Atomistic Modeling of Materials Failure, Springer US, 2008. 